\title{
Characterization of Poly(Safranine T)-Modified Electrode and Application for Simultaneous Determination of Epinephrine and Uric Acid Coexisting with Ascorbic Acid
}

\author{
Lingmei Niu,* Kaoqi Lian, Weijun Kang and Shan Li \\ School of Public Health, Hebei Medical University, Shijiazhuang, 050017 P. R. China
}

\begin{abstract}
Um eletrodo de carbono vítreo modificado com poli(safranina $\mathrm{T}$ ) foi utilizado para a determinação simultânea de epinefrina (EP) e ácido úrico (AU) na presença de ácido ascórbico (AA). Correntes eletrocatalíticas aumentadas e potenciais bem separados para EP e AU foram observados. As correntes de pico anódico de EP e AU foram lineares em função das concentrações correspondentes, na faixa de $6,0 \times 10^{-6}-1,0 \times 10^{-4} \mathrm{~mol} \mathrm{~L}^{-1}$. Além disso, o eletrodo modificado mostrou boa sensitividade e estabilidade. Resultados satisfatórios foram alcançados para a determinação de EP e AU em soluções de injeção de EP bem como em amostras de urina humana.
\end{abstract}

A poly(safranine T) modified glassy carbon electrode was used for the simultaneous determination of epinephrine (EP) and uric acid (UA) in the presence of ascorbic acid (AA). Enhanced electrocatalytic currents and well-separated potentials for EP and UA were observed. The anodic peak currents of EP and UA were linear to the corresponding concentrations in the range of $6.0 \times 10^{-6}-1.0 \times 10^{-4} \mathrm{~mol} \mathrm{~L}^{-1}$. In addition, the modified electrode showed good sensitivity and stability. Satisfactory results were achieved for the determination of EP and UA in injection solutions of EP and in human urine samples.

Keywords: safranine T, glassy carbon electrode, epinephrine, uric acid, ascorbic acid

\section{Introduction}

Uric acid (2,6,8-trihydroxypurine, UA) is the primary end product of purine metabolism. ${ }^{1}$ The normal UA level in serum ranges from $2.4 \times 10^{-4}-5.2 \times 10^{-4} \mathrm{~mol} \mathrm{~L}^{-1}$, and in urinary excretion, the level is typically $1.4 \times 10^{-3}-4.4 \times 10^{-3} \mathrm{~mol} \mathrm{~L}^{-1} .^{2}$ Disorders of purine biosynthesis or purine catabolism, such as gout, hyperuricemia, and Lesch-Nyhan syndrome, are generally caused by an abnormal concentration of UA dissolved in human urine or blood. ${ }^{3}$ Thus, monitoring the concentration of UA in biological fluids may be used as an early warning to the occurrence of these diseases. ${ }^{4}$ In general, electroactive UA can be irreversibly oxidized in aqueous solution, where the major product is allantoin. ${ }^{5}$

Epinephrine (EP), also called adrenaline, is an important catecholamine neurotransmitter in the mammalian central nervous system. It plays an important role in the function of the central nervous, renal, hormonal, and cardiovascular systems. ${ }^{6}$ Changes in its concentration may result in many diseases. ${ }^{7}$ In addition, EP is the common drug of choice

*e-mail: niulm@hebmu.edu.cn as vasoconstrictor, cardiac stimulator and bronchodilator. ${ }^{8}$ Thus, developing a quantitative method for studying EP will significantly help in understanding its effects on the nervous system and any artificial substitutes. The method will be of great significance to pharmacological research and life sciences as well.

Generally, UA and EP coexist in human biological fluids. UA is oxidized at a potential close to that of EP at most solid electrodes, resulting in an overlapping voltammetric response. Hence, the simultaneous detection of UA and EP in a mixture is interesting to biological and chemical researchers. Individual determination of UA and EP have been widely reported, ${ }^{2,8-15}$ whereas simultaneous determination is seldom studied. ${ }^{7,16,17}$ Ascorbic acid (AA) also coexists with UA and EP in human fluids, and the potentials usually overlap. Therefore, the simultaneous determination of UA and EP coexisting with AA is a serious challenge to researchers. ${ }^{18-21}$

Electronically conducting polymers, such as polyazines, polypyrrole, and polythiophene, have received considerable attention because of their possible applications in organic batteries, electrochromic displays, electrocatalysis and 
microelectronic devices. ${ }^{22}$ Among these compounds, polyazines have been widely used as redox indicators and mediators in recent years. ${ }^{23}$ However, focus has been devoted to the redox kinetics and charge transport of polyazine films, ${ }^{24}$ and sensor applications are rarely reported. To our knowledge, there is no known data on the improvement of peak separation during the simultaneous determination of EP and UA in the presence of AA using polyazine-modified electrode. Thus, the compound safranine T (SFR), which is an electroactive polyaromatic cation, ${ }^{25}$ is used to modify a glassy carbon electrode (GCE) in this study. In relation to this, the purpose of this paper is to investigate the electrochemically polymerized SFR modified electrode for the oxidation of EP and UA under the coexistence of AA.

The structure of SFR is shown in Figure 1.

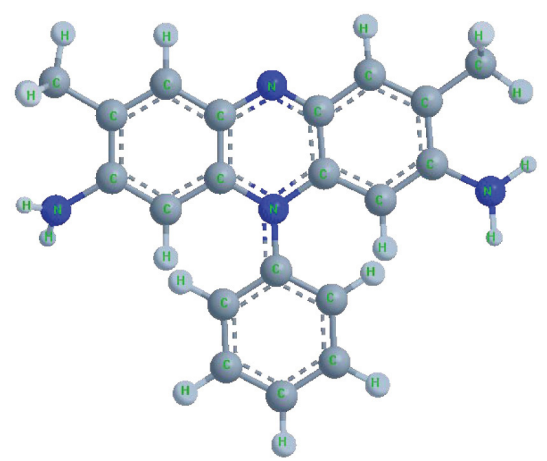

Figure 1. Chemical structure of SFR.

\section{Experimental}

\section{Materials}

Both safranine $\mathrm{T}$ and ascorbic acid were obtained from Shanghai Chemical Reagent Co., Ltd. Uric acid was purchased from Fluka (Buchs, Switzerland). Epinephrine was from Sigma Aldrich (Steinheim, Germany). They were used without further purification. Epinephrine hydrochloride injection solution was purchased from Guangzhou Mingxing Phramaceutical Co., Ltd. All other reagents were of analytical-reagent grade. Doubly distilled water was used throughout the experiments. The temperature of the experiments was set at room temperature (ca. $\left.25^{\circ} \mathrm{C}\right)$.

\section{Apparatus}

Electrochemical measurements were done on an electrochemical analyzer (model AD300, China). The three-electrode system used in the measurements was comprised of a GCE ( $d=3 \mathrm{~mm}$, model P314771) or polySFR-modified electrode as the working electrode, $\mathrm{Pt}$ as the counter electrode (model P314776), and $\mathrm{Ag} / \mathrm{AgCl}$ (KCl-saturated) electrode (model P314794) as the reference electrode. Potentials are given with respect to the $\mathrm{Ag} / \mathrm{AgCl}$ (KCl-saturated) electrode.

\section{Preparation of polySFR modified electrode}

Prior to each experiment, the GCE was polished to a mirror finish with $0.05 \mu \mathrm{m}$ alumina in a water slurry. After polishing, the electrode was rinsed and ultrasonicated with 1:1 (v/v) nitric acid $\left(\mathrm{HNO}_{3}\right)$ solution, acetone, and doubly distilled water for $5 \mathrm{~min}$, successively, to remove any adsorbed substance on the surface. Then, it was dried under nitrogen flow.

The bare GCE was then immersed in $2.0 \times 10^{-3} \mathrm{~mol} \mathrm{~L}^{-1}$ SFR solution containing $0.1 \mathrm{~mol} \mathrm{~L}^{-1}$ sulfuric acid $\left(\mathrm{H}_{2} \mathrm{SO}_{4}\right)$. The polySFR-modified electrode was prepared by potentialsweep electrolysis at a potential scan rate of $50 \mathrm{mV} \mathrm{s}^{-1}$ in the potential range of -0.5 to $1.8 \mathrm{~V} v s$. $\mathrm{Ag} / \mathrm{AgCl}$ (KCl-saturated) electrode for 10 cycles. The electrode was washed with distilled water and stored in phosphate buffer solution $(\mathrm{PB})$ at $\mathrm{pH} 7.0$.

\section{Result and Discussion}

\section{Electropolymerisation of SFR}

The SFR polymerization in $\mathrm{PB}$ of different $\mathrm{pH}(\mathrm{pH} 2.0$ to 7.0) and different electrolytes sulfuric, nitric and hydrochloric acid $\left(\mathrm{H}_{2} \mathrm{SO}_{4}, \mathrm{HNO}_{3}, \mathrm{HCl}\right)$ was investigated. At higher pH, SFR cannot form a stable polymer; that is the same to what was obtained in reference. ${ }^{24} \mathrm{H}_{2} \mathrm{SO}_{4}$ was chosen as the acid electrolyte because the polymerization showed a better response in this solution. The reason is that the addition of $\mathrm{H}_{2} \mathrm{SO}_{4}$ can facilitate film formation. Secondly, potential-sweep electrolysis is more effective in preparing the smooth film than constant potential electrolysis. ${ }^{26}$ The electrode modified in this manner showed a blue-purple, fairly even film. In Figure 2, a pair of redox peaks appear at about $-0.25 \mathrm{~V}$ in the first cycle, probably because of a reversible reduction/reoxidation of the monomer. ${ }^{22}$ Two other anodic waves are formed at 1.1 and $1.5 \mathrm{~V}$, probably because the dimers formed react with other monomer or dimers. ${ }^{24}$ The two anodic waves decrease continuously with potential cycling because of the absence of the corresponding cathodic waves. ${ }^{22}$ As presented in reports, ${ }^{27}$ the growth mechanism for polySFR may be similar to that of polyaniline synthesized via head-to-tail bonding from acidic solutions. Safranine $\mathrm{T}$ is polymerized via 
cation-radical formation at the primary amino group and its linkage to one of the carbon atoms of the aromatic rings. ${ }^{22}$ The possible scheme was provided in the reference 24 . In other words, in order to achieve the polySFR film, one must sweep the electrode potential over a value that oxidizes the $\mathrm{NH}_{2}$ groups of SFR. This accounts for the absence of substantial film formation if the potential sweep is limited to the range of -0.3 to $1.0 \mathrm{~V}$.

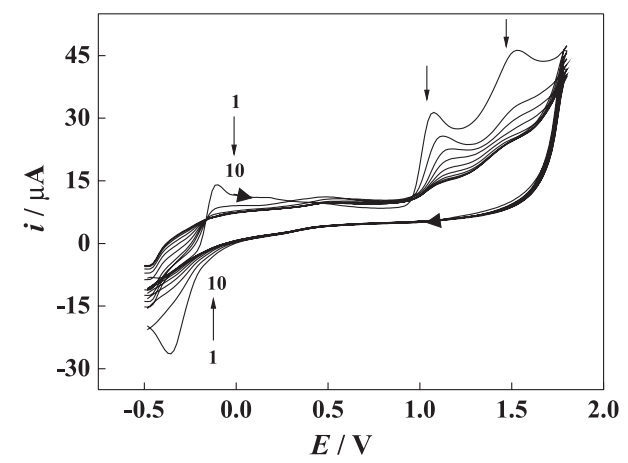

Figure 2. Consecutive CVs recorded during electropolymerization. Electrolyte: $2.0 \times 10^{-3} \mathrm{~mol} \mathrm{~L}^{-1}$ safranine $\mathrm{T}$ solution in $0.1 \mathrm{~mol} \mathrm{~L}^{-1} \mathrm{H}_{2} \mathrm{SO}_{4}$; scan rate: $50 \mathrm{mV} \mathrm{s}^{-1}$.

\section{Effect of cycle number on polySFR formation}

The effect of cycle number on the surface coverage of SFR was demonstrated in a pure $0.1 \mathrm{~mol} \mathrm{~L}^{-1} \mathrm{H}_{2} \mathrm{SO}_{4}$ solution. In Figure 3, a pair of redox waves gradually increases near the $-0.2 \mathrm{~V}$ results from the growth of a polySFR film. The redox potential in $\mathrm{H}_{2} \mathrm{SO}_{4}$ is close to that of the SFR monomer in solution. This indicates that the SFR retained monomer-type redox activity after polymerization. ${ }^{22}$ The improved electronic conductivity of the polymer resulting from the larger cycle number is attributed to an increase in redox peak currents in $\mathrm{H}_{2} \mathrm{SO}_{4}$ solution. However, when the cycle number is above 120 , the polymer on the surface desquamates. The surface coverage of SFR was estimated from cyclic voltammetry (CV) using the following equation: ${ }^{28}$

$\Gamma=\mathrm{Q} /(\mathrm{nFA})$

where $\mathrm{Q}$ is the charge in coulombs, $\mathrm{n}$ is the number of electrons involved in the process, $\mathrm{n}=2,{ }^{22} \mathrm{~F}$ is the Faraday constant, and $\mathrm{A}$ is the geometric area of the working electrode. The surface coverage of the polymer also develops with increasing cycle number (Figure 4). The slope of the linear region gives a growth rate of $2.9 \times 10^{-11} \mathrm{~mol} \mathrm{~cm}^{-2}$ per cycle.

On the other hand, for polySFR produced at 20 cycles, the anodic peak current increases almost linearly with the

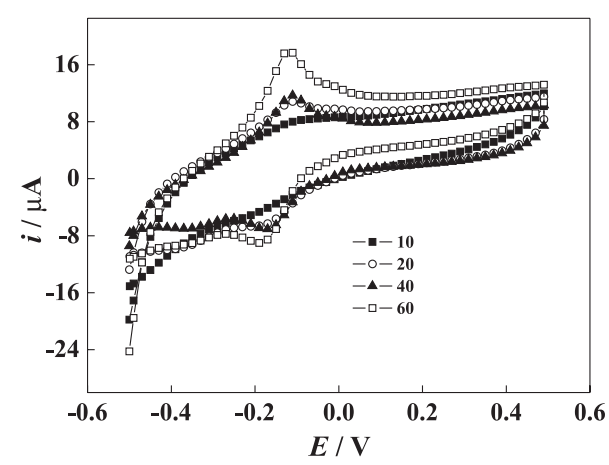

Figure 3. $\mathrm{CV}$ s in a pure $0.1 \mathrm{~mol} \mathrm{~L}^{-1} \mathrm{H}_{2} \mathrm{SO}_{4}$ solution after polySFR was formed at different cycles.

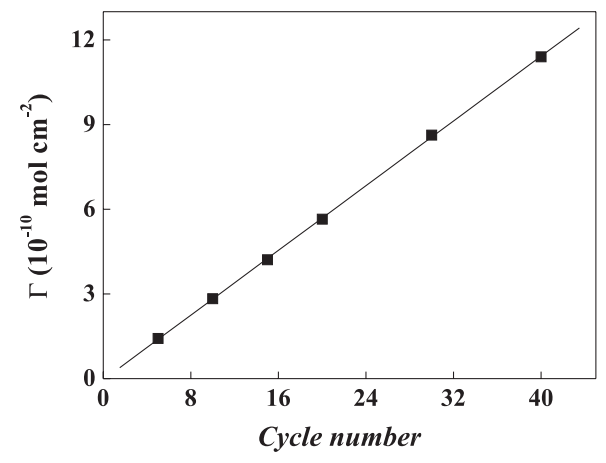

Figure 4. Effect of cycle number on the surface coverage.

square root of the scan rate up to $200 \mathrm{mV} \mathrm{s}^{-1}$. This indicates that the redox process is controlled by the diffusion-like electron transport in the polymer. When the cycle number is extended to 100 , the relationship between the peak current and scan rate is maintained. Thus, the increased cycle number does not change the redox mechanism of the polymer, and the surface process is always controlled by the diffusion of electrons. From above, the obtained result is different from that for phenosafranine presented in literature. ${ }^{22}$

However, the developing response of EP and UA cannot be obtained at the polySFR electrode at increasing cycle numbers. In Figure 5, the peak currents of EP and UA from the polySFR electrode during the oxidation process have a maximum at 20 cycles. It then decreases with an increase in cycle number. The thick layer blocks the electron transfer during the EP or UA oxidation in the film. For this reason, a cycle number of 20 was selected for use in further experiments.

Simultaneous determination of EP and UA and the effect of solution $\mathrm{pH}$

Differential pulse voltammograms (DPV) of EP and UA under the potential windows of $0.0-0.7 \mathrm{~V}$ using the bare electrode (Figure $6 \mathrm{c}$ ) and the polySFR-modified electrode 


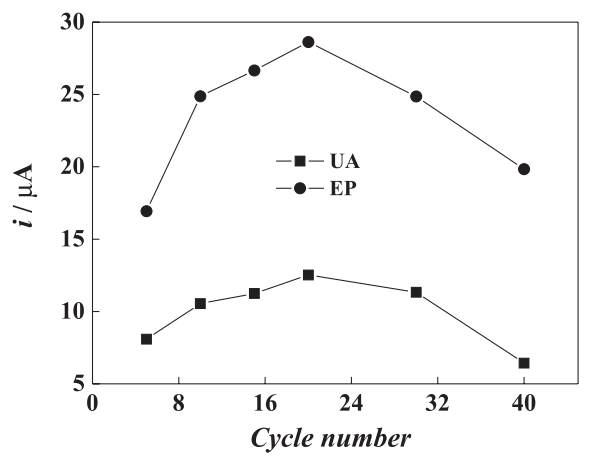

Figure 5. Effect of cycle number on the response of EP and UA oxidation. $C_{\mathrm{EP}}: 3.0 \times 10^{-4} \mathrm{~mol} \mathrm{~L}^{-1} ; C_{\mathrm{UA}}: 3.0 \times 10^{-4} \mathrm{~mol} \mathrm{~L}^{-1}$.

(Figure 6a) were obtained in $\mathrm{PB}$ at $\mathrm{pH}$ 5.4. Curve $\mathrm{b}$ is the DPV of the modified electrode in blank PB. In Figure 6, the unmodified GC electrode cannot separate the EP and UA oxidation peaks. No obvious anodic oxidation peaks are formed at the bare GC electrode (curve c). In curve a, the anodic peak potentials representing EP and UA oxidations are 0.28 and $0.45 \mathrm{~V}$, respectively, for the modified electrode. EP and UA can be monitored separately, and the peak currents can increase remarkably compared with the bare electrode. When individual species, such as EP or UA, are taken into account, oxidation also takes place with an increase in peak current compared with the bare GC electrode. The individual oxidation potential of EP or UA is the same as that of mixture. The results represent the favorable effect of the polySFR film. It shows that it can be used to observe the kinetics of the electron transfer of EP and UA on the surface of the modified electrode. When the polySFR-modified electrode is immersed in a solution containing EP and UA for $5 \mathrm{~s}$ and then kept in $0.1 \mathrm{~mol} \mathrm{~L}^{-1}$ PB for cyclic scanning, oxidation currents due to EP and UA are not observed. This shows that EP and UA were not adsorbed on the modified electrode, which has been proven by the relationship between the anodic peak currents of EP

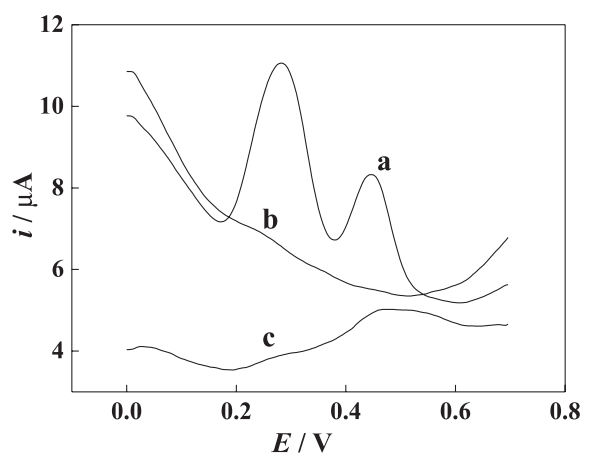

Figure 6. DPVs recorded using the polySFR-modified electrode $(\mathrm{a}, \mathrm{b})$ and bare GC electrode (c) in the presence of a mixture containing $1.0 \times 10^{-4} \mathrm{~mol} \mathrm{~L}^{-1} \mathrm{EP}$ and $1.0 \times 10^{-4} \mathrm{~mol} \mathrm{~L}^{-1} \mathrm{UA}(\mathrm{a}, \mathrm{c})$; and absence of the mixture (b). Phosphate buffer: $\mathrm{pH} 5.4$; scan rate: $50 \mathrm{mV} \mathrm{s}^{-1}$. and UA, and the scan rates. The plot of the anodic peak current $\left(i_{\mathrm{pa}}\right)$ against the square root of the scan rate $\left(v^{1 / 2}\right)$ is linear for EP and UA at the SFR film-modified electrode, indicating that the oxidation of EP and UA is controlled by diffusion..$^{29}$

The enhanced signals of EP and UA can be understood through the following mechanism. PolySFR, the structure of which is similar to the poly(phenosafranine), is a kind of cationic polymer. ${ }^{23}$ Dougherty demonstrated that the cation- $\pi$ interaction can cause synthetic hosts to develop novel binding selectivity and high affinities for highly water-soluble guests. ${ }^{30}$ Therefore, soluble species, such as EP and UA, can accumulate on the polySFR film by molecular interaction. This pertains to hydrogen bonding with the proton donating group of polySFR. Consequently, this favorable condition increases oxidation current sensitivity.

To verify the practicality of polySFR-modified electrode for the simultaneous determination of EP and UA, mixtures of these species were investigated. Figure 7 is the DPV graph of different concentrations of EP and UA. According to the experimental results, the concentrations are linearly related to the corresponding peak currents in the range of $6.0 \times 10^{-6}-1.0 \times 10^{-4} \mathrm{~mol} \mathrm{~L}^{-1}$, with detection limits of $2.0 \times 10^{-7} \mathrm{~mol} \mathrm{~L}^{-1}$ for EP and $4.3 \times 10^{-6} \mathrm{~mol} \mathrm{~L}^{-1}$ for UA. The linear equation is $i_{\mathrm{p}}=0.3873+0.4130 C(\mathrm{r}=0.9975)$ for $\mathrm{EP}$ and $i_{\mathrm{p}}=0.0519+0.2014 C(\mathrm{r}=0.9981)$ for $\mathrm{UA}$, respectively. Based on the results, EP and UA have no interaction with each other and can be determined simultaneously using the modified electrode.

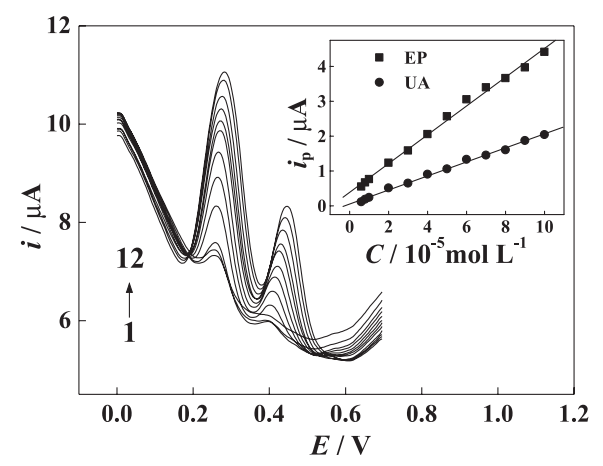

Figure 7. DPVs of EP and UA at different concentrations. Concentrations of EP $\left(10^{-5} \mathrm{~mol} \mathrm{~L}^{-1}\right)$ : (1) 0.6 , (2) 0.8 , (3) 1.0, (4) 2.0, (5) 3.0, (6) 4.0, (7) 5.0, , (8) 6.0, , (9) 7.0, (10) 8.0, (11) 9.0, (12) 10; concentrations of UA $\left(10^{-5} \mathrm{~mol} \mathrm{~L}^{-1}\right)$ : (1) 0.6 , (2) 0.8 , (3) 1.0 , (4) 2.0, (5) 3.0, (6) 4.0, (7) 5.0, (8) 6.0, (9) 7.0, (10) 8.0, (11) 9.0, (12) 10; inset graphs are the plots of anodic peak currents to the corresponding concentrations of EP and UA.

The influence of solution $\mathrm{pH}$ on the simultaneous response of EP and UA at the modified electrode was investigated using $\mathrm{CV}$. The effect of $\mathrm{pH}$ on the oxidation peak currents is shown in Figure 8. Both the plots of EP 
and UA increase with $\mathrm{pH}$ enhancement and reach their maximum at $\mathrm{pH} 7.0$ and 4.4 , respectively, before decreasing significantly. The probable reason is the protonation of $\mathrm{EP}\left(\mathrm{pK}_{\mathrm{a}}=8.88\right)$ and $\mathrm{UA}\left(\mathrm{pK}_{\mathrm{a} 1}=5.40\right)^{17}$ when the $\mathrm{pH}$ is below 8.88 for EP and 5.40 for UA. Another reason is the maximum interaction between the polySFR film and both $\mathrm{EP}$ and UA when $\mathrm{pH}$ rises to 7.0 and 4.4. To obtain a good response signal from both EP and UA, pH 5.4 was selected as the condition for measurement.

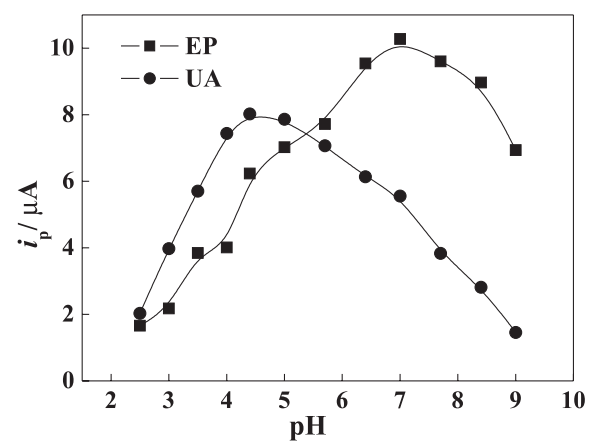

Figure 8. Effect of $\mathrm{pH}$ on the oxidation of EP and UA using polySFR-modified electrode measured by cyclic voltammetry. $C_{\mathrm{EP}}: 1.0 \times 10^{-4} \mathrm{~mol} \mathrm{~L}^{-1} ; C_{\mathrm{UA}}: 1.0 \times 10^{-3} \mathrm{~mol} \mathrm{~L}^{-1}$.

\section{$D P V$ of $E P$ and $U A$ in the presence of $A A$}

AA exists in human fluids. Thus, simultaneous determination of EP and UA in the presence of AA is important. Figure 9 shows the DPV curves of $1.3 \times 10^{-4} \mathrm{~mol} \mathrm{~L}^{-1} \mathrm{EP}$ and $9.0 \times 10^{-5} \mathrm{~mol} \mathrm{~L}^{-1}$ UA solutions containing $1.0 \times 10^{-3} \mathrm{~mol} \mathrm{~L}^{-1} \mathrm{AA}$ using the bare (dashed line) and polySFR film-modified electrodes (solid line). A broad oxidation peak is present when the bare GCE is used, and the peak potentials of EP, UA, and AA are indistinguishable. In contrast, the polySFR film on the GCE resolves the mixed voltammetric response into three well-defined voltammetric peaks at $0.0,0.3$ and $0.4 \mathrm{~V}$, corresponding to the oxidations of AA, EP, and UA, respectively. A substantial increase in peak current is also observed. This indicates the suitability of the modified electrode for the determination of EP and $\mathrm{UA}$ in the presence of AA.

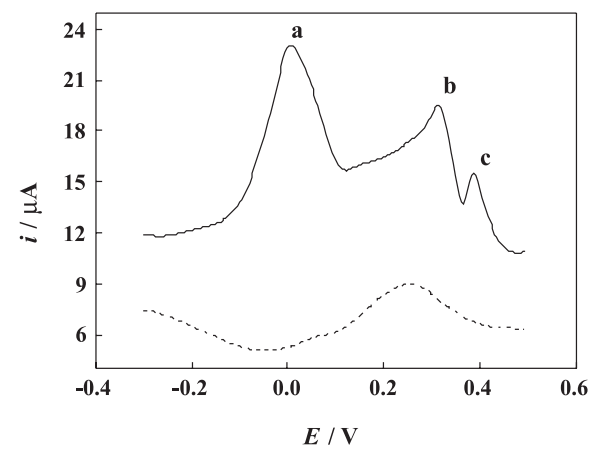

Figure 9. DPVs of the mixture containing (a) AA $\left(1.0 \times 10^{-3} \mathrm{~mol} \mathrm{~L}^{-1}\right)$, (b) EP $\left(1.3 \times 10^{-4} \mathrm{~mol} \mathrm{~L}^{-1}\right)$, and (c) UA $\left(9.0 \times 10^{-5} \mathrm{~mol} \mathrm{~L}^{-1}\right)$ at the polySFR-modified electrode (solid line) and bare GCE (dashed line).

Table 1 shows a comparison for the determination of EP and UA at polySFR modified electrode with various polymer electrodes. The comparison shows that the suggested electrode can be used for the determination of EP and UA in biological fluids and pharmaceutical products over a wide range of concentrations with low detection limits.

\section{Stability of the polySFR-modified electrode}

In order to evaluate the stability of the modified electrode, a series of repetitive measurements were carried out in solutions containing $1.0 \times 10^{-5} \mathrm{~mol} \mathrm{~L}^{-1} \mathrm{EP}$ and UA. The peak current variations are 4 and 3\% for an average

Table 1. Comparison of different modified GC electrode for the determination of EP and UA with polySFR modified electrode

\begin{tabular}{|c|c|c|c|c|c|c|c|}
\hline Electrode & Compound & $\begin{array}{l}\text { Linear range } \\
\left(\mathrm{mol} \mathrm{L}^{-1}\right)\end{array}$ & $\begin{array}{l}\text { Detection limit } \\
\quad\left(\mathrm{mol} \mathrm{L}^{-1}\right)\end{array}$ & Real samples & $\begin{array}{l}\text { Concomitant } \\
\text { compounds }\end{array}$ & Methods & Reference \\
\hline \multirow{2}{*}{ PPyox-GCE } & $\mathrm{EP}$ & $3.0 \times 10^{-7}-2.1 \times 10^{-5}$ & $3.0 \times 10^{-8}$ & EP injection & \multirow{2}{*}{ AA } & \multirow{2}{*}{ DPV } & \multirow{2}{*}{17} \\
\hline & UA & $5.0 \times 10^{-8}-2.8 \times 10^{-5}$ & $1.2 \times 10^{-8}$ & Urine & & & \\
\hline \multirow{2}{*}{ P-ATT-GCE } & $\mathrm{EP}$ & $5.0 \times 10^{-6}-4.5 \times 10^{-5}$ & - & EP injection & \multirow{2}{*}{ AA, xanthine } & \multirow{2}{*}{ DPV } & \multirow{2}{*}{18} \\
\hline & UA & - & - & Urine & & & \\
\hline \multirow{2}{*}{ Poly(caffeic acid)-GCE } & EP & $2.0 \times 10^{-6}-8.0 \times 10^{-5}$ & $2.0 \times 10^{-7}$ & EP injection & \multirow{2}{*}{ AA } & \multirow{2}{*}{$\mathrm{CV}$} & \multirow{2}{*}{19} \\
\hline & UA & $5.0 \times 10^{-6}-3.0 \times 10^{-4}$ & $6.0 \times 10^{-7}$ & - & & & \\
\hline \multirow{2}{*}{ MWCNT-GCE } & EP & $1.3 \times 10^{-5}-8.0 \times 10^{-5}$ & - & EP injection & \multirow{2}{*}{ AA } & \multirow{2}{*}{ DPV } & \multirow{2}{*}{20} \\
\hline & UA & $2.7 \times 10^{-5}-2.4 \times 10^{-4}$ & - & Urine & & & \\
\hline \multirow{2}{*}{ PolySFR-GCE } & $\mathrm{EP}$ & $6.0 \times 10^{-6}-1.0 \times 10^{-4}$ & $2.0 \times 10^{-7}$ & EP injection & \multirow{2}{*}{ AA } & \multirow{2}{*}{ DPV } & \multirow{2}{*}{ This work } \\
\hline & UA & $6.0 \times 10^{-6}-1.0 \times 10^{-4}$ & $4.3 \times 10^{-6}$ & Urine & & & \\
\hline
\end{tabular}


Table 2. Determination of EP and UA in mixtures $(n=5)$

\begin{tabular}{|c|c|c|c|c|c|c|c|c|}
\hline \multicolumn{3}{|c|}{ Added $\left(\mu \mathrm{mol} \mathrm{L}{ }^{-1}\right)$} & \multicolumn{3}{|c|}{$\mathrm{EP}$} & \multicolumn{3}{|c|}{ UA } \\
\hline $\mathrm{EP}$ & AA & UA & $\begin{array}{c}\text { Found } \\
\left.(\mu \mathrm{mol} \mathrm{L})^{-1}\right)\end{array}$ & Recovery (\%) & $\operatorname{RSD}(\%)$ & $\begin{array}{c}\text { Found } \\
\left.(\mu \mathrm{mol} \mathrm{L})^{-1}\right)\end{array}$ & Recovery (\%) & $\operatorname{RSD}(\%)$ \\
\hline- & - & - & 19.4 & 97.0 & 3.2 & - & - & - \\
\hline 20.0 & 20.0 & 20.0 & 39.7 & 99.2 & 1.6 & 19.7 & 98.5 & 1.5 \\
\hline 40.0 & 40.0 & 20.0 & 60.1 & 100 & 1.8 & 20.3 & 102 & 2.3 \\
\hline 60.0 & 60.0 & 40.0 & 78.8 & 98.5 & 2.2 & 40.9 & 102 & 1.6 \\
\hline
\end{tabular}

Table 3. Determination of EP and UA in human urine samples $(n=5)$

\begin{tabular}{|c|c|c|c|c|c|c|c|c|}
\hline \multicolumn{3}{|c|}{ Added $\left(\mu \mathrm{mol} \mathrm{L}{ }^{-1}\right)$} & \multicolumn{3}{|c|}{$\mathrm{EP}$} & \multicolumn{3}{|c|}{ UA } \\
\hline $\mathrm{EP}$ & UA & AA & $\begin{array}{c}\text { Found } \\
\left.(\mu \mathrm{mol} \mathrm{L})^{-1}\right)\end{array}$ & Recovery (\%) & $\mathrm{RSD}(\%)$ & $\begin{array}{c}\text { Found } \\
(\mu \mathrm{mol} \mathrm{L}-1)\end{array}$ & Recovery (\%) & $\operatorname{RSD}(\%)$ \\
\hline- & - & - & - & - & - & 27.1 & - & - \\
\hline 20.0 & 20.0 & 20.0 & 19.8 & 99.0 & 2.6 & 48.3 & 103 & 2.7 \\
\hline 40.0 & 40.0 & 40.0 & 39.5 & 98.8 & 1.4 & 65.3 & 97.3 & 3.4 \\
\hline 60.0 & 60.0 & 60.0 & 59.9 & 99.8 & 1.7 & 86.3 & 99.1 & 1.9 \\
\hline
\end{tabular}

of 30 determinations of EP and UA, respectively. This indicates that the modified electrode has an excellent ability to prevent fouling due to the oxidation products. No apparent decrease is observed after storing in $0.1 \mathrm{~mol} \mathrm{~L}^{-1}$ $\mathrm{PB}(\mathrm{pH} 7.0)$ at $4{ }^{\circ} \mathrm{C}$ for 30 days. This is confirmed by the retention of $87 \%$ current response to EP and UA.

\section{Interference study}

The influence of various foreign species on the determination of $1.0 \times 10^{-5} \mathrm{~mol} \mathrm{~L}^{-1} \mathrm{EP}$ and UA was investigated. The tolerance limit was taken as the maximum concentration of the foreign substances that can cause approximately $\pm 5 \%$ relative error in determination. The tolerated ratio of foreign substances is 100 for $\mathrm{Na}^{+}, \mathrm{Cl}^{-}, \mathrm{K}^{+}$, $\mathrm{Mg}^{2+}$, and $\mathrm{Ca}^{2+} ; 50$ for L-lysine, glucose, and L-asparagines; 30 for glutamic acid, glycine, L-cystine and L-cysteine; and 10 for acetaminophen and NADH.

\section{Sample analysis}

The epinephrine hydrochloride injection solution (specified content of EP is $1.00 \mathrm{mg} \mathrm{mL}^{-1}$ ) was diluted to $2.0 \times 10^{-5} \mathrm{~mol} \mathrm{~L}^{-1}$ with distilled water. The diluted EP injection solutions and standard EP, UA and AA solutions were added to a series of $10 \mathrm{~mL}$ measuring flasks and diluted to the mark with $0.1 \mathrm{~mol} \mathrm{~L}^{-1} \mathrm{~PB}$ (pH 5.4). Differential pulse voltammograms were recorded, and the anodic peak currents were measured. The standard addition method was used to calculate the concentrations of EP, UA, and AA. The results are satisfactory (Table 2).
Human urine samples were also tested. Four samples were analyzed using the proposed method, and all the samples were diluted 100 times. The results are shown in Table 3. The total value of uric acid in urine samples is $2.71 \times 10^{-3} \mathrm{~mol} \mathrm{~L}^{-1}$. This was obtained by multiplying the detected value with the dilution factor.

\section{Conclusions}

PolySFR was used to modify a GCE, and the polymeric conditions were investigated. The polySFR-modified electrode not only separated the voltammetric peaks of EP, UA, and AA well but also showed that these species had a good electrocatalytic activity. The anodic peak currents of EP and UA were linear to the corresponding concentrations. Satisfactory results were also obtained in the analysis of real samples using the polySFR-modified electrode.

\section{Acknowledgments}

The project was supported by the Natural Science Foundation of Hebei Province (No. C2007000813).

\section{References}

1. Thiagarajan, S.; Chen, S. M.; Talanta 2007, 74, 212.

2. Behera, S.; Raj, R.; Biosens. Bioelectron. 2007, 23, 556.

3. Liu, A. H.; Honma, I.; Zhou, H. S.; Biosens. Bioelectron. 2007, $23,74$.

4. Wang, G. F.; Meng, J.; Fang, B.; Electrochim. Acta 2008, 53, 2837. 
5. Wang, P.; Li, Y. X.; Talanta 2007, 73, 431.

6. Li, Y.; Chen, S. M.; Anal. Biochem. 2009, 388, 288.

7. Bouhouti, H. E.; Naranjo-Rodriguez, I.; Talanta 2009, 79, 22.

8. Ly, S. Y.; Kim, M. H.; Microchem. J. 2006, 82, 113.

9. Zhou, M.; Guo, L. P.; Electrochim. Acta 2008, 53, 4176.

10. Zeng, Y. H.; Yang, J. Q.; Wu, K. B.; Electrochim. Acta 2008 , 53,4615 .

11. Gong, J. M.; Lin, X. Q.; Electrochim. Acta 2004, 49, 4351.

12. Hason, S.; Vetterl, V.; Electrochim. Acta 2009, 54, 1864.

13. Miah, M. R.; Ohsaka, T.; Electrochim. Acta 2008, 54, 316.

14. Lu, L. P.; Lin, X. Q.; Electrochem. Commun. 2008, 10, 704.

15. Ndamanisha, C. J.; Guo, L. P.; Biosens. Bioelectron. 2008, 23 , 1680.

16. Beitollahi, H.; Ardakani, M. M.; Biosens. Bioelectron. 2008, 24,362 .

17. Li, J.; Lin, X. Q.; Anal. Chim. Acta 2007, 596, 222.

18. Palraj, K.; John, S. A.; Anal. Chim. Acta 2009, 647, 97.
19. Ren, W.; Luo, H. Q.; Li, N. B.; Biosens. Bioelectron. 2006, 21, 1086.

20. Hamid, R. Z.; Navid, N.; Sens. Actuators, B 2010, 143, 666.

21. Nada, F. A.; Maher, F. E.; Ahmed, G.; Anal. Biochem. 2010, $400,78$.

22. Komura, T.; Ishihara, M.; J. Electroanal. Chem. 2000, $493,84$.

23. Selvaraju, T.; Ramaraj, R.; Electrochem. Commun. 2003, 5, 667.

24. Rasa, P.; Ausra, S.; Albertas, M.; Christopher, M. A. B.; Thin Solid Films 2009, 517, 5435.

25. Herrero, R.; Guidelli, R.; J. Electroanal. Chem. 1997, 425, 87.

26. Ohsaka, T.; Tanaka, K.; J. Chem. Soc. Chem. 1993, 3, 222.

27. Zhou, D. M.; Sun, J. J.; Electrochim. Acta 1998, 43, 1803.

28. Li, N. B.; Kwak, J. Y.; Biosens. Bioelectron. 2008, 23, 1519.

29. Li, N. B.; Niu, L. M.; Luo, H. Q.; Microchim. Acta 2006, 153, 37.

30. Kearney, P. C.; Mizoue, L. S.; J. Am. Chem. Soc. 1993, 115, 9907. 